\title{
Reforço ao cisalhamento com fibras de carbono em vigas-parede sem aberturas: estudos experimentais
}

Este trabalho tem por objetivo apresentar resultados de estudos experimentais sobre o reforço ao cisalhamento de vigas-parede de concreto armado sem aberturas por meio do uso de materiais compósitos de resina e fibras de carbono (CFRP). Os parâmetros variados das vigas-parede de concreto foram as dimensões, as armaduras internas, e o tipo de carregamento das vigas-parede, a resistência do concreto à compressão, e o tipo, a configuração e a quantidade de CFRP colado. Constatou-se que o tipo, a configuração e taxa de armadura de reforço, a resistência do concreto à compressão, a relação entre o vão de cisalhamento e a altura útil e a taxa de armadura interna das vigas são os parâmetros mais influentes no comportamento das vigas-parede de concreto armado reforçadas ao cisalhamento com CFRP colados.

Palavras-chave: Reforço; Vigas-parede; Concreto armado; Fibras de carbono.

\section{Carbon fiber shear reinforcement in unobstructed wall beams: experimental studies}

\begin{abstract}
This paper aims to present the results of experimental researches about reinforced concrete deep beam without openings on strengthened in shear with carbon fiber reinforced plastics (CFRP). The varied parameters were the dimensions, the internal reinforcements, the loading scheme, the compressive strength of concrete, and the type, configuration and the amount of CFRP bonded. It was found that the type, configuration and reinforcement ratio of FRP, the compressive strength of concrete, the dimensions and position of web openings in beams, the shear span ratio and the internal reinforcement ratio of beams are the most influential parameters in the behavior of shear strengthened reinforced concrete deep beams with bonded FRP.
\end{abstract}

Keywords: Strengthened; Deep beams; Reinforced concrete; Carbon fibers.

\section{Topic: Engenharia Urbana}

Reviewed anonymously in the process of blind peer.
Received: 10/04/2018

Approved: 24/05/2018
Fábio Grisolia de Ávila

Instituto Militar de Engenharia, Brasil

http://lattes.cnpq.br/0047461869347858

fabiogavila@gmail.com

Ana Maria Abreu Jorge Teixeira

Instituto Militar de Engenharia, Brasil

http://lattes.cnpq.br/1454254574734029

anam@ime.eb.er

Luiz Antonio Vieira Carneiro

Instituto Militar de Engenharia, Brasil

http://lattes.cnpq.br/2431901858566512

carneiro@ime.eb.br
Referencing this:

ÁVILA, F. G.; TEIXEIRA, A. M. A. J.; CARNEIRO, L. A. V.. Reforço ao cisalhamento com fibras de carbono em vigas-parede sem aberturas: estudos experimentais. Revista Ibero Americana de Ciências Ambientais, v.9, n.4, p.235-252, 2018. DOI:

http://doi.org/10.6008/CBPC2179-6858.2018.004.0020 


\section{INTRODUÇÃO}

Vigas-parede são vigas de altura grande o suficiente de modo que não são consideradas elementos lineares. Conforme Leonhardt et al. (1978), a hipótese de Bernoulli não se aplica no caso de vigas-parede, pois as seções não permanecem planas sob a ação das cargas, mesmo para um material perfeitamente elástico. De acordo com a norma ABNT NBR 6118 (2014), vigas-parede são vigas em que a relação entre o seu vão e a sua altura (L/h) é inferior a 2, em vigas biapoiadas, e inferior a 3, em vigas contínuas.

Segundo Kore et al. (2013), não há consenso entre as principais normas internacionais sobre os limites da razão L/h que diferenciam as vigas e as vigas-parede. Na Inglaterra, o manual CIRIA GUIDE 2 (1984) define vigas-parede como as vigas com esta razão menor que 2, para vigas biapoiadas, e menor que 2,5, para vigas contínuas; nos Estados Unidos da América, segundo a norma ACl-318M (2011), todas as vigas com a razão menor que 4 são vigas-parede; e no Canadá, de acordo com o código CSA-A23.3 (2004), vigas-parede são vigas que possuem o vão de cisalhamento menor que o dobro de sua altura.

Conforme Heiza et al. (2012), as vigas-parede são frequentemente utilizadas em diversas aplicações estruturais, tais como paredes diafragmas, pontes, reservatórios de água, peças pré-moldadas de concreto protendido, fundações, silos, abrigos subterrâneos, estruturas offshore e edifícios altos. De acordo com Patel et al. (2014), o reforço de elementos estruturais, como vigas e pilares, torna-se vital hoje em dia, muitas vezes por circunstâncias inevitáveis, como a revisão das condições de carregamento, a mudança nas condições de ocupação e a deterioração da estrutura existente devido aos efeitos ambientais.

Segundo Islam et al. (2005), compósitos de fibras de alta resistência não metálicas, feitos com fibras de carbono, vidro ou aramida encapsuladas em uma matriz polimérica sob a forma de arames, barras, fios, telas armadas em cruz, lâminas, tiras ou mantas, têm mostrado grande potencial como reforço de estruturas de concreto, particularmente onde a durabilidade é a preocupação principal. Estes materiais são conhecidos como compósitos de resina e fibras (FRP), podendo ser de três tipos: compósitos de resina e fibras de carbono (CFRP), compósitos de resina e fibras de vidro (GFRP) e compósitos de resina e fibras de aramida (AFRP). Patel et al. (2012) afirmam que, dentre os três tipos de FRP, o CFRP é o que apresenta melhor eficácia no aumento da capacidade resistente ao cisalhamento de vigas.

De acordo com Ekenel et al. (2004), o CFRP propicia adicional reforço na flexão ou no cisalhamento. A confiabilidade na aplicação deste material depende de como ele está aderido ao concreto e o quanto de tensão o concreto pode transferir para o compósito de CFRP. Segundo Khudair et al. (2015), o CFRP oferece ao engenheiro projetista excelentes propriedades que não estão disponíveis em materiais tradicionais. Este material de reforço é resistente à corrosão e possui maior resistência e rigidez em relação ao aço.

Alferjani et al. (2013) mencionam que as aplicações de FRP na engenharia civil podem ser divididas em três grandes grupos: novas construções, reparação e reconstrução. De acordo com estes autores, o primeiro reparo no local por FRP colados externamente foi em 1991. Após o terremoto Hyogoken Nanbu, em 1995, no Japão, houve um aumento repentino na utilização de materiais FRP. Desde então, o reforço de estruturas com o uso de materiais FRP colados externamente tem sido estudado em todo o mundo. Desta 
forma, este trabalho tem por objetivo apresentar resultados de estudos experimentais sobre o reforço ao cisalhamento de vigas-parede de concreto armado sem aberturas por meio do uso de materiais compósitos de resina e fibras de carbono (CFRP).

\section{METODOLOGIA}

Com o intuito de descrever o estado da arte sobre reforço em vigas-parede de concreto armado sem aberturas com materiais compósitos de resina e fibras de carbono, realizou-se uma revisão bibliográfica sistemática, aplicando-se a metodologia da revisão integrativa. De acordo com Botelho (2011), este método deve seguir as seguintes etapas: Identificação do tema e seleção da questão de pesquisa; Estabelecimento de critérios de inclusão e exclusão de artigos e pesquisas; Identificação dos estudos pré-selecionados e selecionados; Categorização dos estudos selecionados; Análise e interpretação dos resultados; e apresentação da revisão/ síntese do conhecimento.

Dessa forma, procurou-se, na base de dados do Portal Periódicos da CAPES e do Google Acadêmico, trabalhos sobre reforço com fibras de carbono em vigas-parede de concreto armado sem aberturas. Para isso, utilizou-se as seguintes palavras-chave: reforço de vigas-parede; strengthening deep beams; deep beams strengthened. Os critérios de inclusão foram os trabalhos que possuíam reforço com materiais compósitos de resina e fibras de carbono colados externamente. Os critérios de exclusão foram os trabalhos não experimentais ou cujo reforço ocorria apenas em vigas-parede com aberturas. Foram encontrados apenas nove estudos com estas características.

\section{DISCUSSÃO TEÓRICA}

\section{Moren (2002)}

Moren (2002) estudou o reforço ao cisalhamento de oito vigas-parede de $914 \mathrm{~mm} \mathrm{x} 228 \mathrm{~mm} \mathrm{x}$ $101 \mathrm{~mm}$ de dimensões, com mesma armadura longitudinal, sem armadura de cisalhamento, com tiras de compósito de resina e fibras de carbono (CFRP) laminado. As vigas foram divididas em dois grupos, conforme o tipo de carregamento: uma carga central ou duas cargas nos terços do vão, respectivamente. 0 primeiro grupo era constituído de vigas com concreto de resistência média à compressão de 42,4 MPa e armadura esquematizada pela Figura 1. Enquanto o segundo grupo era constituído de vigas com concreto de resistência média à compressão de 42,8 MPa e armadura esquematizada pela Figura 2.

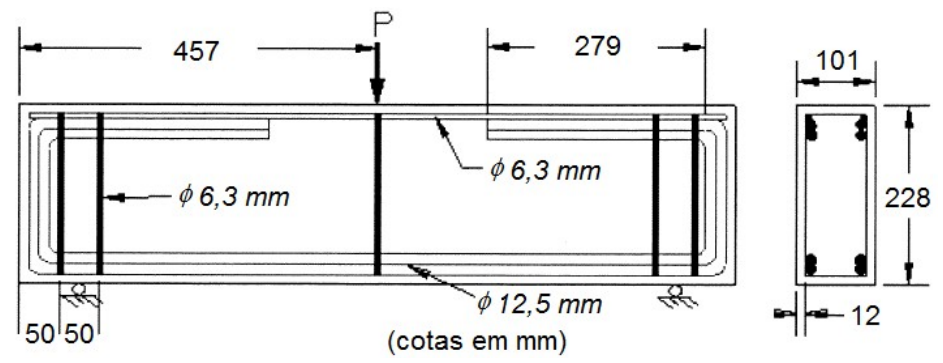

Figura 1: Armadura das vigas do Grupo 1 de Moren (2002). 


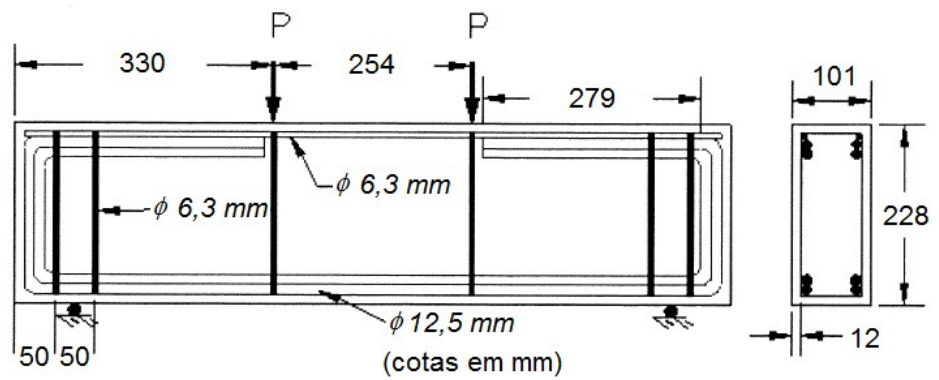

Figura 2: Armadura das vigas do Grupo 2 de Moren (2002).

O reforço utilizado neste estudo foi o Sika CarboDur laminado de $50 \mathrm{~mm}$ de largura, cujas propriedades estão descritas na Tabela 1. As vigas estudadas foram reforçadas ao cisalhamento em três diferentes inclinações ( 0 ㅇ, 45 e 90ㅇ), conforme esquematizado na Figura 3 e resultados apresentados na Tabela 2.

Tabela 1: Propriedades do reforço utilizado por Moren (2002).

\begin{tabular}{|l|l|}
\hline Propriedades & Sika CarboDur Laminado \\
\hline Tipo & Laminado de fibra de carbono pultrado \\
\hline Resistência à tração & $2.800 \mathrm{MPa}$ \\
\hline Módulo de elasticidade & $165 \mathrm{GPa}$ \\
\hline Deformação última & $1,9 \%$ \\
\hline Espessura nominal & $1,2 \mathrm{~mm}$ \\
\hline
\end{tabular}
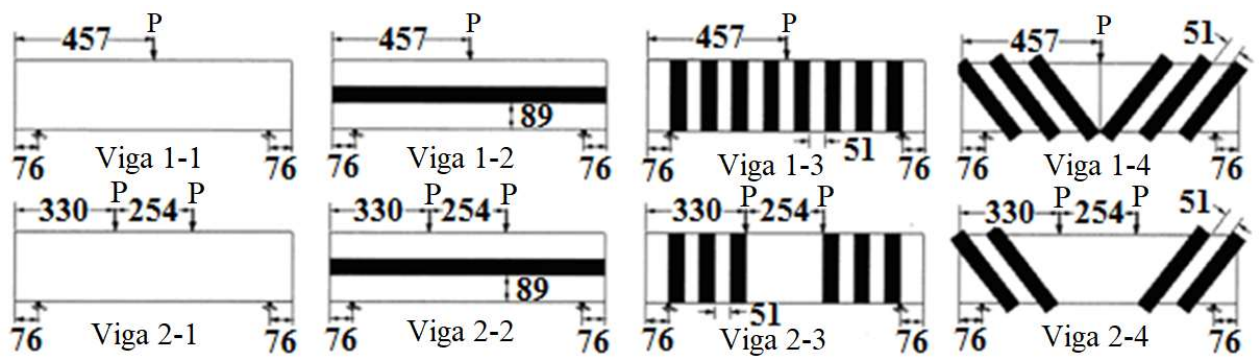

(cotas em $\mathrm{mm}$ )

Figura 3: Configuração do reforço das vigas estudadas por Moren (2002).

Tabela 2: Resultados obtidos por Moren (2002).

\begin{tabular}{|l|l|l|}
\hline Número da viga & Carga última $(\mathrm{kN})$ & Flecha para carga última $(\mathrm{mm})$ \\
\hline $1-1$ & 94,3 & 2,31 \\
\hline $1-2$ & 97,9 & 2,07 \\
\hline $1-3$ & 168,1 & 3,29 \\
\hline $1-4$ & 193,5 & 5,22 \\
\hline $2-1$ & 144,6 & 1,94 \\
\hline $2-2$ & 204,2 & 2,75 \\
\hline $2-3$ & 207,7 & 3,10 \\
\hline $2-4$ & 240,7 & 2,78 \\
\hline
\end{tabular}

O autor concluiu que o reforço a 45 ㅇ foi o mais eficaz e que a 0, o menos, sendo inexpressivo para o caso de carga central. O reforço com CFRP laminado colado externamente melhorou a capacidade de uso e a ductilidade da maioria das vigas ensaiadas, com exceção da viga 1-2 que não obteve melhora significativa.

\section{Zhang (2003)}

Zhang (2003) investigou o comportamento do cortante em vigas de concreto armado reforçadas ao cortante com laminados de CFRP colados externamente. Para isso, dividiu sua pesquisa em três partes: vigas 
esbeltas reforçadas ao cortante com CFRP; vigas-parede reforçadas ao cortante com CFRP; e vigas danificadas ao cortante reforçadas ao cortante com CFRP. Durante seu trabalho, foram testadas 11 vigas esbeltas, das quais cinco tinham comprimento de $1.220 \mathrm{~mm}$ e seis tinham $1.830 \mathrm{mmm}$, e 16 vigas-parede com $914 \mathrm{~mm}$ de comprimento. Todas as vigas foram carregadas por um sistema de teste MTS TestStar II, com capacidade de $1.000 \mathrm{kN}$.

Todas as vigas-parede estudadas tinham $914 \mathrm{~mm}$ x $228 \mathrm{~mm}$ x $101 \mathrm{~mm}$ de dimensões, com concreto de resistência média à compressão de 42,5 MPa e foram divididas em quatro grupos com quatro vigas cada, de acordo com o carregamento realizado (uma carga central ou duas cargas nos terços da viga) e o tipo de CFRP utilizado como reforço (tiras de Sika CarboDur ou tecido de SikaWarp Hex 230c). As Figuras 4 a 7 ilustram as configurações do reforço utilizado para cada viga estudada e a Tabela 3 apresenta as propriedades dos CFRP utilizados.

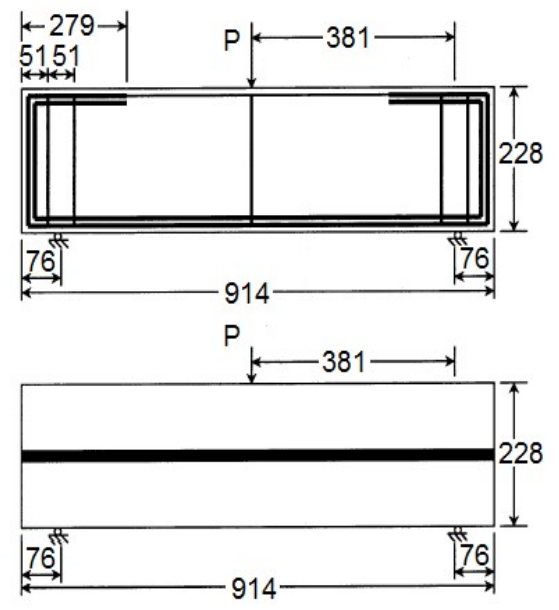

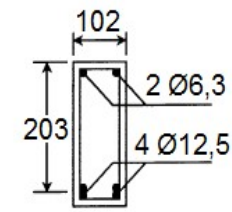

Viga Z11-SC

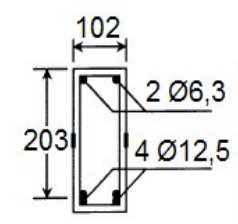

Viga Z11-S0

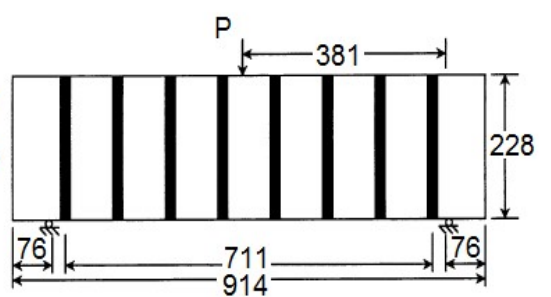

$P$

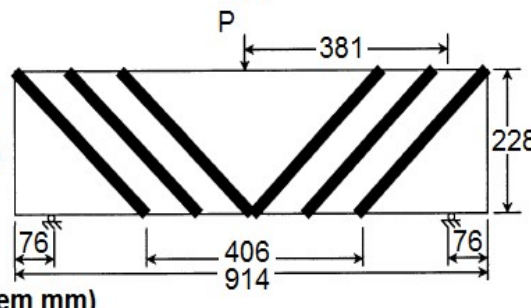

914

(cotas em mm)
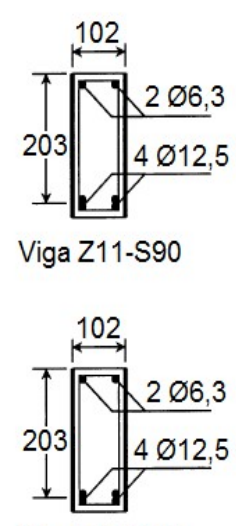

Viga Z11-S45

Figura 4: Vigas-parede do grupo 1 estudadas por Zhang (2003).

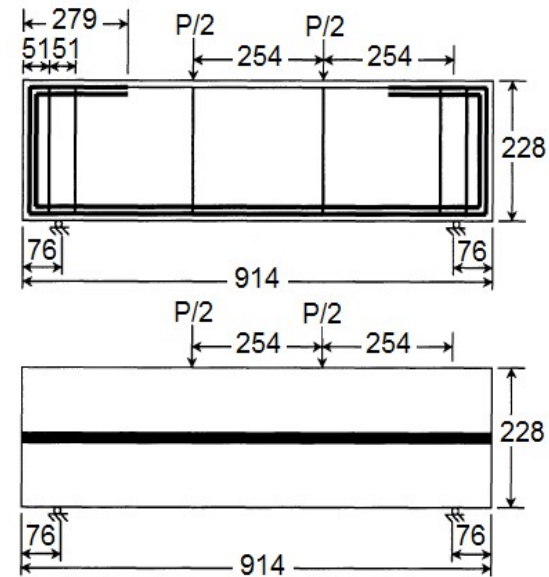

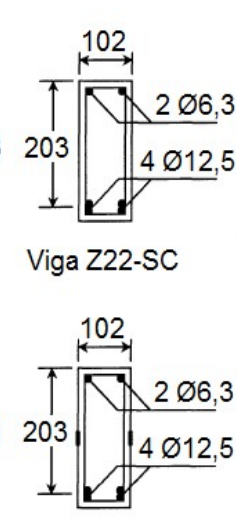

Viga Z22-S0
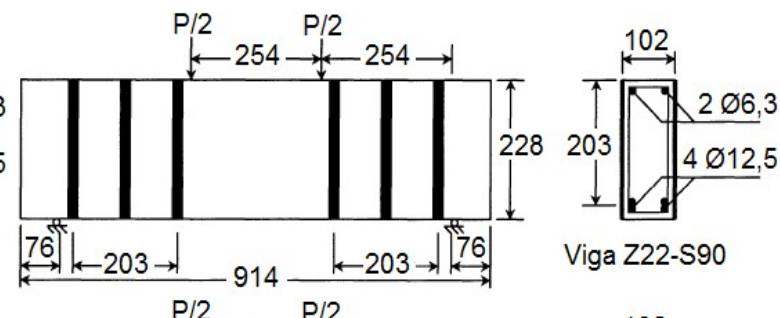

Viga Z22-S90

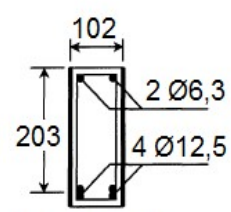

Viga Z22-S45

(cotas em mm)

Figura 5: Vigas-parede do grupo 2 estudadas por Zhang (2003). 

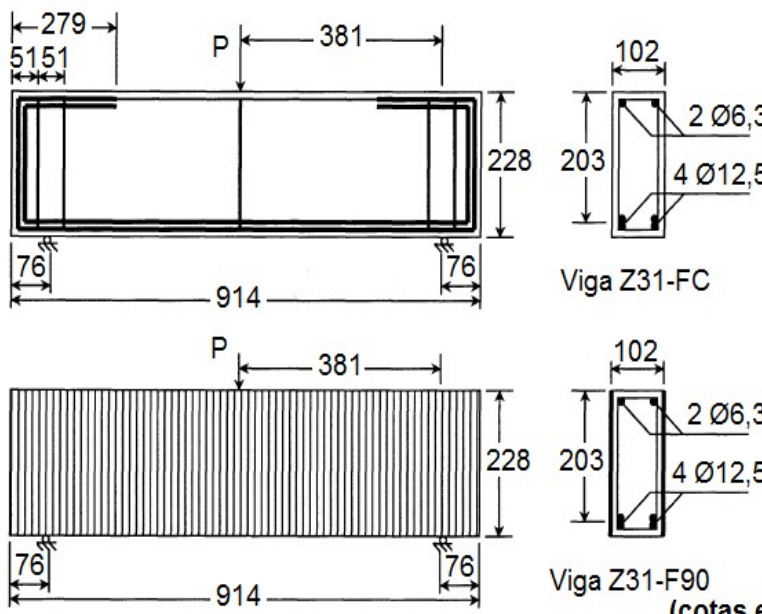

Viga Z31-FC
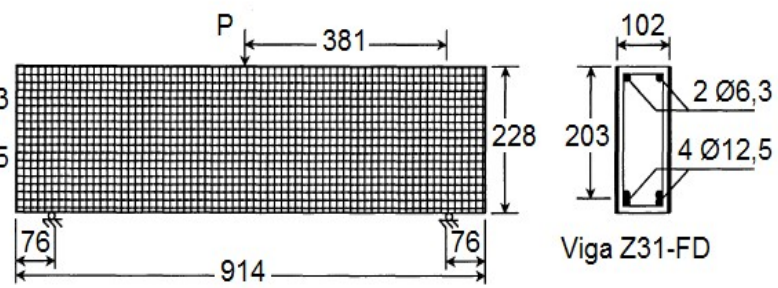

Viga Z31-FD

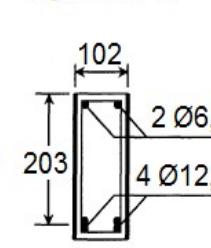

Viga Z31-F90
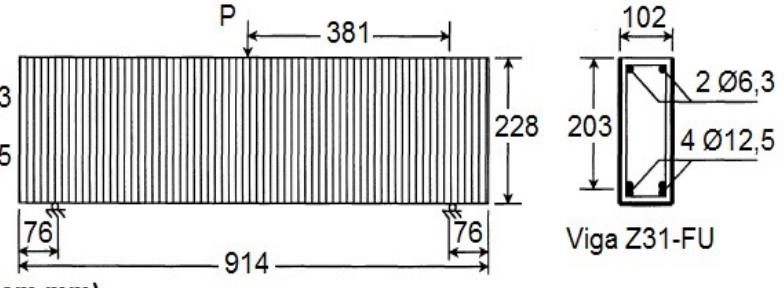

Viga Z31-FU

(cotas em mm)

Figura 6: Vigas-parede do grupo 3 estudadas por Zhang (2003).
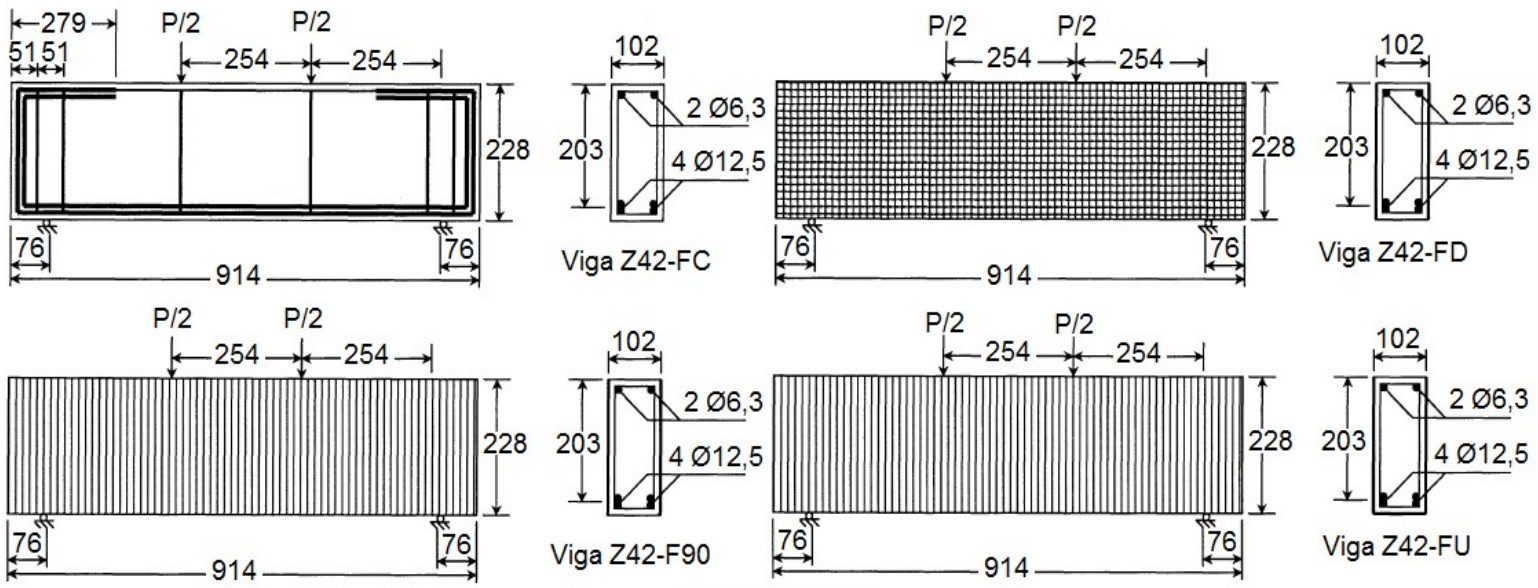

Viga Z42-FD

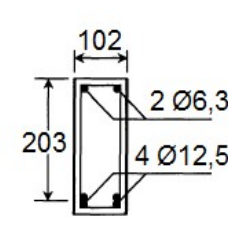

Viga Z42-F90
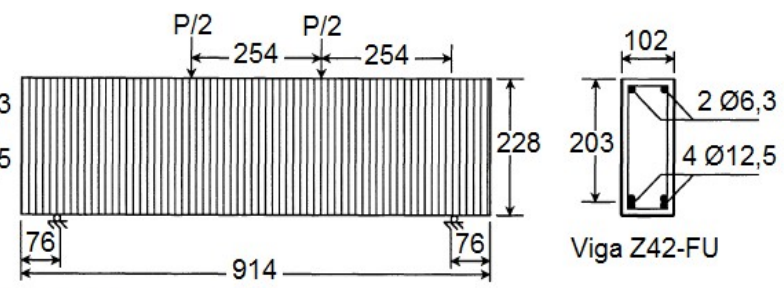

Viga Z42-FU

(cotas em mm)

Figura 7: Vigas-parede do grupo 4 estudadas por Zhang (2003).

Tabela 3: Propriedades dos reforços utilizados por Zhang (2003).

\begin{tabular}{|l|l|l|}
\hline Propriedades & Tiras de Sika CarboDur & SikaWrap Hex 230c \\
\hline Tipo & Laminado de fibra de carbono pultrado & Tecido unidirecional de fibra de carbono \\
\hline Resistência à tração & $2.800 \mathrm{MPa}$ & $960 \mathrm{MPa}$ \\
\hline Módulo de elasticidade & $165 \mathrm{GPa}$ & $73,1 \mathrm{GPa}$ \\
\hline Deformação última & $1,9 \%$ & $1,33 \%$ \\
\hline Espessura nominal & $1,2 \mathrm{~mm}$ & $0,33 \mathrm{~mm}$ \\
\hline
\end{tabular}

O autor observou que o reforço com CFRP colado externamente nas vigas-parede estudadas aumentou a capacidade de carga e a ductilidade destas vigas. Este aumento variou de acordo com a configuração do reforço, conforme apresentado na Tabela 4. Após ensaiadas as vigas, reparou-se as vigas de controle do grupo 1, 2 e 3 (Z11-SC, Z22-SC e Z31-FC, respectivamente) preenchendo-se as fissuras de cisalhamento com a resina SikaDur 35 Hi-Mod LV (resistência à tração aos 14 dias de 58 MPa e módulo de elasticidade de 2,8 GPa) e reforçando-as com a configuração do reforço mais eficiente do respectivo grupo. A Tabela 5 mostra os resultados obtidos por Zhang (2003) nesta etapa da pesquisa.

O autor concluiu que o reforço com CFRP pode aumentar significativamente a capacidade de serviço, a ductilidade e a resistência última ao cortante de uma viga de concreto armado se for escolhida uma adequada configuração do reforço; quando a razão a/d diminuiu, a resistência ao cortante da viga aumentou; e que a injeção de resina epóxi nas fissuras é altamente recomendada para a reparação da viga ao cortante. 
Tabela 4: Resultados obtidos por Zhang (2003) para o reforço de vigas-parede.

\begin{tabular}{|l|l|l|l|}
\hline Viga & Carga última (P) (kN) & Flecha para carga última (mm) & Modo de ruptura \\
\hline Z11-SC & 94,7 & 1,80 & Fissuração diagonal \\
\hline Z11-S0 & 98,8 & 1,83 & Delaminação do reforço \\
\hline Z11-S90 & 169,5 & 2,88 & Delaminação do reforço \\
\hline Z11-S45 & 193,9 & 4,82 & Delaminação do reforço \\
\hline Z22-SC & 145,9 & 1,77 & Fissuração diagonal \\
\hline Z22-S0 & 207,7 & 2,56 & Delaminação do reforço \\
\hline Z22-S90 & 209,1 & 2,82 & Delaminação do reforço \\
\hline Z22-S45 & 242,9 & 2,55 & Delaminação do reforço \\
\hline Z31-FC & 86,3 & 2,13 & Fissuração diagonal \\
\hline Z31-F90 & 154,4 & 2,65 & Delaminação do reforço \\
\hline Z31-FD & 175,3 & 3,27 & Delaminação do reforço \\
\hline Z31-FU & 192,2 & 3,47 & Delaminação do reforço \\
\hline Z42-FC & 175,3 & 3,00 & Fissuração diagonal \\
\hline Z42-F90 & 257,6 & 3,22 & Delaminação do reforço \\
\hline Z42-FD & 266,9 & 3,29 & Delaminação do reforço \\
\hline Z42-FU & 255,3 & 3,51 & Delaminação do reforço \\
\hline
\end{tabular}

Tabela 5: Resultados obtidos por Zhang (2003) para as vigas-parede reparadas.

\begin{tabular}{|l|l|l|l|}
\hline Viga & Carga última $(\mathbf{P})(\mathbf{k N})$ & Flecha para carga última $(\mathbf{m m})$ & Modo de ruptura \\
\hline Z11-SC & 94,7 & 1,801 & Fissuração diagonal \\
\hline Z11-S45 & 193,9 & 4,818 & Delaminação do reforço \\
\hline Z11-SCR45 & 165,5 & 3,043 & Delaminação do reforço \\
\hline Z22-SC & 145,9 & 1,768 & Fissuração diagonal \\
\hline Z22-S45 & 242,9 & 2,553 & Delaminação do reforço \\
\hline Z22-SCR45 & 266,9 & 3,104 & Delaminação do reforço \\
\hline Z31-FC & 86,3 & 2,129 & Fissuração diagonal \\
\hline Z31-FU & 192,2 & 3,470 & Delaminação do reforço \\
\hline Z31-FCRU & 214,8 & 3,531 & Delaminação e ruptura do reforço \\
\hline
\end{tabular}

Islam et al. (2005)

Islam et al. (2005) avaliaram o comportamento do reforço em seis vigas-parede de $2.000 \mathrm{~mm} \times 800$ mm x 120 mm de dimensões e mesma armadura com o uso de CFRP em diferentes configurações, sob a ação de duas cargas concentradas. As vigas estudadas possuíam concreto com resistência à compressão de corpode-prova cilíndrico de 37,8 MPa, resistência à tração por compressão diametral de 3,7 MPa e armadura esquematizada pela Figura 8.

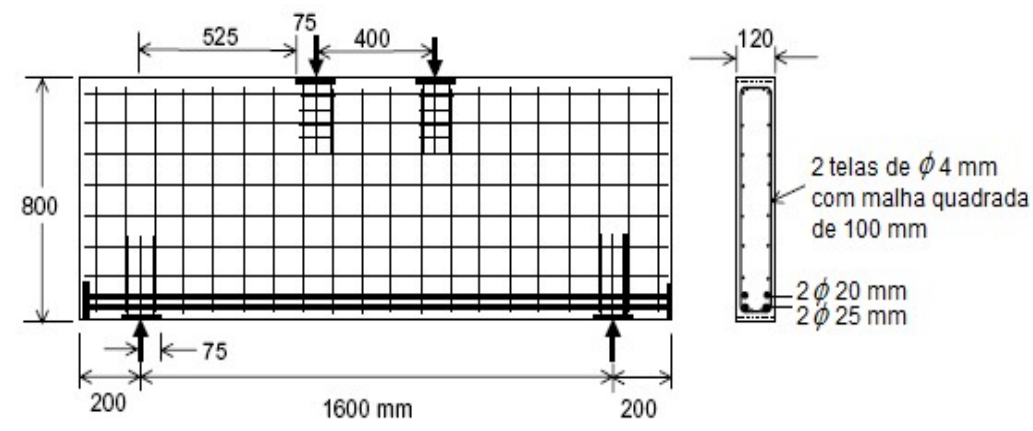

Figura 8: Armadura das vigas-parede estudadas por Islam et al. (2005).

Três diferentes compósitos de resina e fibras de carbono foram utilizados para reforçar as vigasparede estudadas: manta (MBrace 130), tiras (SIKA) e telas armadas em cruz (NEFMAC). As propriedades mecânicas dos compósitos utilizados estão apresentadas na Tabela 6 e a Figura 9 mostra as configurações de reforço ao cisalhamento estudadas. 
Os autores concluíram que o uso de sistemas de FRP acarretou um crescimento das fissuras diagonais muito menor e aumentou a capacidade resistente da viga estudada, como ilustram a Figura 10 e a Tabela 7. Embora todos os sistemas de reforço foram quase igualmente eficazes, o reforço com telas armadas em cruz coladas com orientação normal demonstrou ser o sistema mais eficaz com relação à quantidade de material utilizado.

Tabela 6: Propriedades dos reforços utilizados por Islam et al. (2005).

\begin{tabular}{|l|l|l|l|l|l|l|}
\hline $\begin{array}{l}\text { Material } \\
\text { CFRP }\end{array}$ & $\begin{array}{l}\text { Largura } \\
(\mathbf{m m})\end{array}$ & $\begin{array}{l}\text { Espessura } \\
(\mathbf{m m})\end{array}$ & $\begin{array}{l}\text { Área Seção Transversal } \\
\left(\mathbf{m m}^{\mathbf{2}}\right)\end{array}$ & $\begin{array}{l}\text { Resistência à Tração } \\
(\mathbf{M P a})\end{array}$ & $\begin{array}{l}\text { Módulo } \\
\text { Elasticidade (GPa) }\end{array}$ & $\begin{array}{l}\text { de } \\
\text { Última (\%) }\end{array}$ \\
\hline Manta & - & 0,165 & - & 3.480 & 230 & 1,5 \\
\hline Tira & 50 & 1,2 & 60,0 & 3.050 & 165 & 1,7 \\
\hline Malha 1 & - & - & 6,6 & 1.200 & 100 & 1,2 \\
\hline Malha 2 & - & - & 17,5 & 1.200 & 100 & 1,2 \\
\hline Malha 3 & - & - & 39,2 & 1.200 & 100 & 1,2 \\
\hline
\end{tabular}

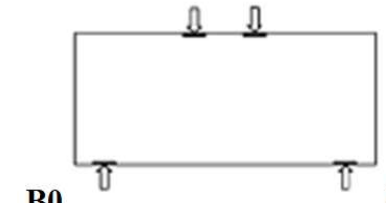

B0

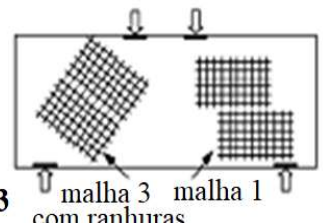

B1

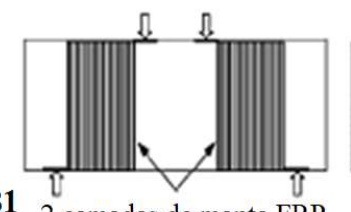

2 camadas de manta FRP

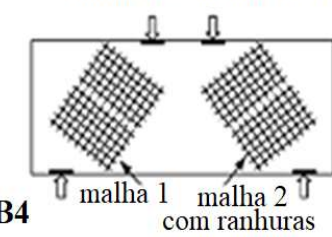

B2
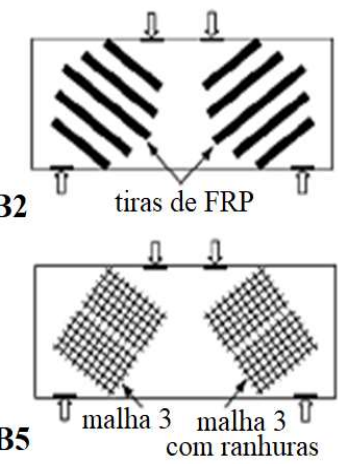

Figura 9: Esquema das vigas-parede estudadas por Islam et al. (2005).
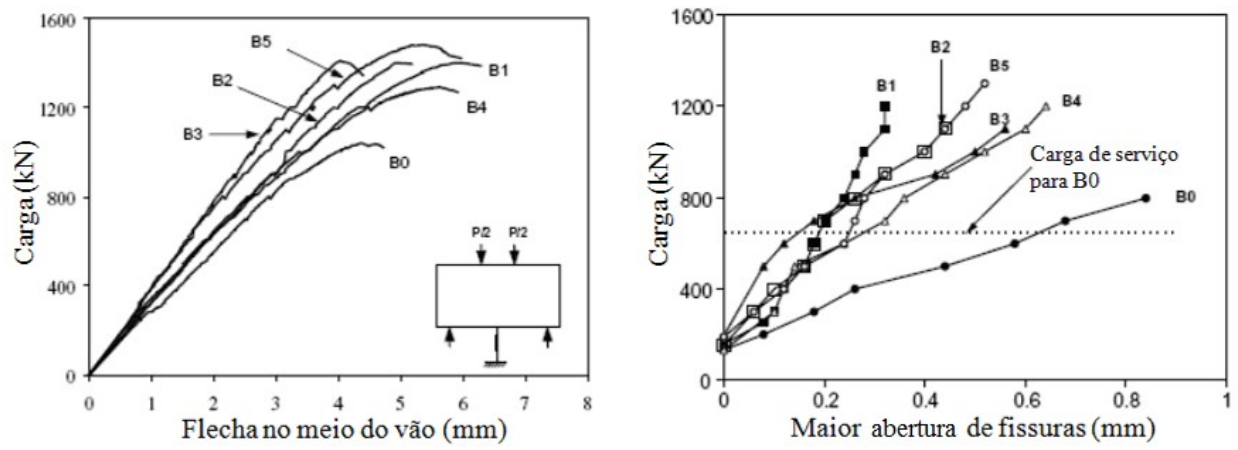

Figura 10: Comportamento das vigas estudadas por Islam et al. (2005).

Tabela 7: Resultados encontrados por Islam et al. (2005).

\begin{tabular}{|l|l|l|l|}
\hline \multirow{2}{*}{ Viga } & Carga de primeira fissura & \multirow{2}{*}{ Carga última (kN) } \\
\cline { 2 - 4 } & Flexão $(\mathbf{k N})$ & Diagonal (kN) & 1.040 \\
\hline B0 & 130 & 280 & 1.402 \\
\hline B1 & 160 & - & 1.400 \\
\hline B2 & 150 & 370 & 1.410 \\
\hline B3 & 195 & 490 & 1.292 \\
\hline B4 & 130 & 350 & 1.482 \\
\hline B5 & 190 & 330 & \\
\hline
\end{tabular}

Lee et al. (2011)

Lee et al. (2011) estudaram o comportamento do reforço ao cisalhamento com folhas de CFRP coladas externamente em 14 vigas-parede de concreto armado de seção transversal em forma de ' $T$ '. Todas as vigas tinham a mesma armadura, $1.800 \mathrm{~mm}$ de comprimento, $460 \mathrm{~mm}$ de altura total, $100 \mathrm{~mm}$ de altura 
da mesa, $180 \mathrm{~mm}$ de largura da alma e $450 \mathrm{~mm}$ de largura da mesa, conforme apresentado na Figura 11, e o concreto possuía resistência média à compressão de 22,5 MPa e módulo de elasticidade de 22,7 GPa.
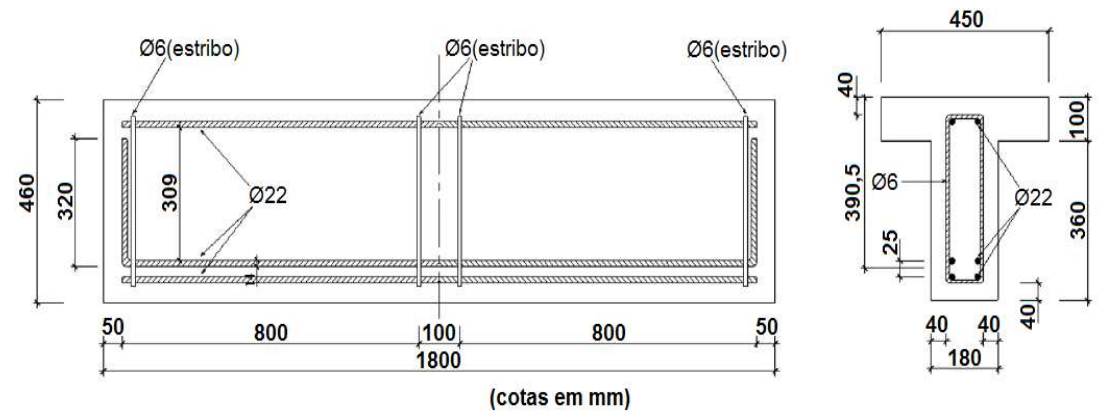

Figura 11: Armadura das vigas-parede estudadas por Lee et al. (2011).

Nesta pesquisa, os autores variaram o comprimento de reforço das folhas de CFRP (um quarto, meio ou o comprimento total do vão de cisalhamento), a combinação das direções das fibras das folhas de CFRP $\left(0^{\circ} / 0^{\circ}, 90^{\circ} / 90^{\circ}, 90^{\circ} / 0^{\circ}\right.$ e $\left.45^{\circ} / 135^{\circ}\right)$, além de utilizar um reforço de folhas de CFRP colados em "U". A Figura 12 e a Tabela 8 ilustram a configuração do ensaio e o do reforço, respectivamente. A Tabela 9 apresenta as propriedades do reforço utilizado.

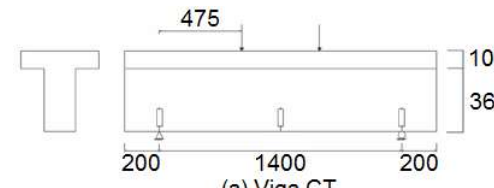

(a) Viga CT

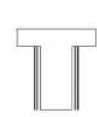

475

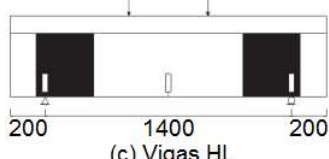

(c) Vigas HL

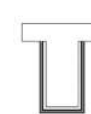

475

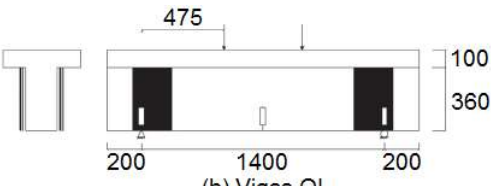

(b) Vigas QL

475

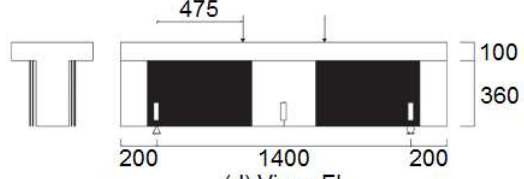

(d) Vigas FL

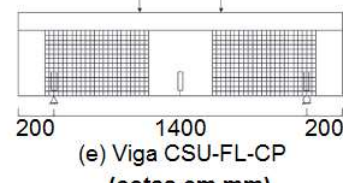

(cotas em mm)

Figura 12: Representação esquemática das vigas estudadas por Lee et al. (2011).

Tabela 8: Configuração do reforço das vigas estudadas por Lee et al. (2011).

\begin{tabular}{|l|c|c|c|}
\hline \multicolumn{1}{|c|}{ Viga } & Configuração do reforço & Comprimento do reforço & Direção das fibras \\
\hline CT & - & - & - \\
\hline CS-QL-HP & Apenas nos lados & Um quarto do vão de cisalhamento & $0^{\circ} / 0^{\circ}$ \\
\hline CS-QL-VP & Apenas nos lados & Um quarto do vão de cisalhamento & $90^{\circ} / 90^{\circ}$ \\
\hline CS-QL-CP & Apenas nos lados & Um quarto do vão de cisalhamento & $90^{\circ} / 0^{\circ}$ \\
\hline CS-QL-AP & Apenas nos lados & Um quarto do vão de cisalhamento & $45^{\circ} / 135^{\circ}$ \\
\hline CS-HL-HP & Apenas nos lados & Metade do vão de cisalhamento & $0^{\circ} / 0^{\circ}$ \\
\hline CS-HL-VP & Apenas nos lados & Metade do vão de cisalhamento & $90^{\circ} / 90^{\circ}$ \\
\hline CS-HL-CP & Apenas nos lados & Metade do vão de cisalhamento & $90^{\circ} / 0^{\circ}$ \\
\hline CS-HL-AP & Apenas nos lados & Metade do vão de cisalhamento & $45^{\circ} / 135^{\circ}$ \\
\hline CS-FL-HP & Apenas nos lados & Vão de cisalhamento & $0^{\circ} / 0^{\circ}$ \\
\hline CS-FL-VP & Apenas nos lados & Vão de cisalhamento & $90^{\circ} / 90^{\circ}$ \\
\hline CS-FL-CP & Apenas nos lados & Vão de cisalhamento & $90^{\circ} / 0^{\circ}$ \\
\hline CS-FL-AP & Apenas nos lados & Vão de cisalhamento & $45^{\circ} / 135^{\circ}$ \\
\hline CSU-FL-CP & Envolvimento em 'U' & Vão de cisalhamento & $90^{\circ} / 0^{\circ}$ \\
\hline
\end{tabular}


Os autores concluíram que o comprimento de reforço das folhas de CFRP teve uma influência significativa no desempenho das vigas-parede para todas as combinações estudadas (Tabela 10); para o mesmo comprimento, o reforço com duas camadas horizontais apresentou maior resistência ao cisalhamento; e o reforço colado em ' $U$ ' mostrou ser muito eficaz no aumento da capacidade de carga, na rigidez inicial e na ductilidade, devido ao efeito de ancoragem.

Tabela 9: Propriedades do reforço utilizado por Lee et al. (2011).

\begin{tabular}{|l|l|}
\hline Propriedades & Folha de CFRP \\
\hline Fabricante & Hankook Carbon, Inc. \\
\hline Resistência à tração & $3.475 \mathrm{MPa}$ \\
\hline Módulo de elasticidade & $230 \mathrm{GPa}$ \\
\hline Deformação última & $1,5 \%$ \\
\hline Espessura nominal & $0,11 \mathrm{~mm}$ \\
\hline
\end{tabular}

Tabela 10: Resultados encontrados por Lee et al. (2011).

\begin{tabular}{|l|l|l|l|}
\hline \multirow{2}{*}{ Viga } & \multicolumn{2}{|l|}{ Carga de primeira fissura } & \multirow{2}{*}{ Carga última (kN) } \\
\cline { 2 - 4 } & Flexão $\mathbf{( k N )}$ & Cisalhamento $(\mathbf{k N})$ & 458,2 \\
\hline CT & 55,9 & 161,8 & 528,6 \\
\hline CS-QL-HP & 68,6 & 222,6 & 505,9 \\
\hline CS-QL-VP & 80,2 & 222,1 & 512,9 \\
\hline CS-QL-CP & 60,8 & 231,4 & 525,3 \\
\hline CS-QL-AP & 76,5 & 224,6 & 599,4 \\
\hline CS-HL-HP & 68,8 & 333,4 & 528,6 \\
\hline CS-HL-VP & 82,4 & 286,4 & 562,7 \\
\hline CS-HL-CP & 85,3 & 318,7 & 547,2 \\
\hline CS-HL-AP & 78,5 & 323,6 & 760,5 \\
\hline CS-FL-HP & 78,6 & - & 542,1 \\
\hline CS-FL-VP & 76,5 & - & 660,5 \\
\hline CS-FL-CP & 78,5 & - & 646,5 \\
\hline CS-FL-AP & 107,9 & - & 699,5 \\
\hline CSU-FL-CP & 103,0 & - & \\
\hline
\end{tabular}

\section{Asghari et al. (2014)}

Asghari et al. (2014) estudaram o comportamento do reforço ao cisalhamento com folhas de CFRP e laminados de CFRP colados externamente em seis vigas-parede de mesma armadura, sendo cinco de 1.500 $\mathrm{mm} \times 500 \mathrm{~mm} \times 120 \mathrm{~mm}$ de dimensões e uma de $1.500 \mathrm{~mm}$ x $450 \mathrm{~mm}$ x $120 \mathrm{~mm}$ de dimensões (v. Figura 13). Todas as vigas possuíam concreto com resistência média à compressão em corpo de prova cúbico de $30 \mathrm{MPa}$ e armadura com tensão de escoamento de 400 MPa.

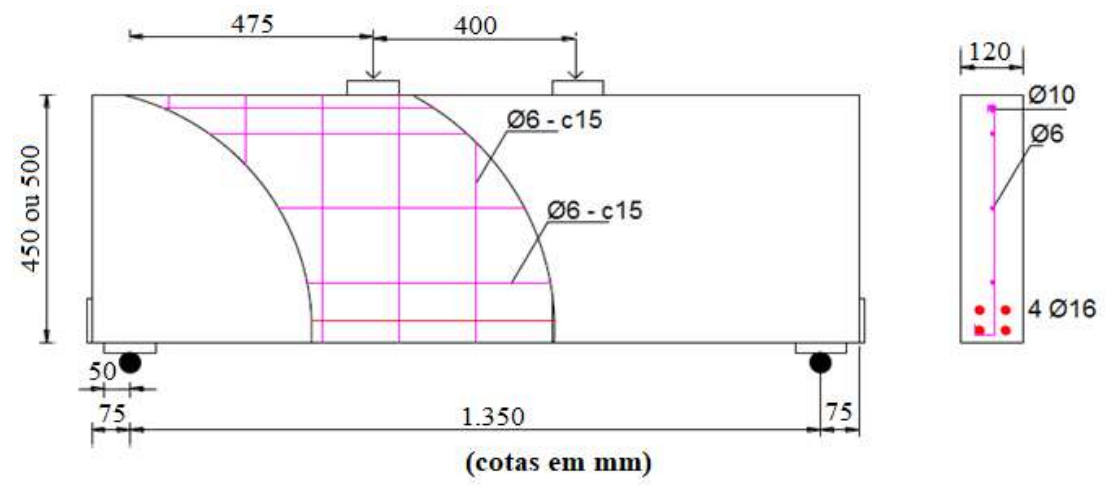

Figura 13: Armadura das vigas-parede estudadas por Asghari et al. (2014). 
Nesta pesquisa, variaram-se o tipo de reforço e sua configuração, conforme esquematizado na Tabela 11. A Tabela 12 mostra as propriedades de cada reforço utilizado e a Figura 14 e a Tabela 13 apresentam os resultados obtidos pelos autores. Os autores concluíram que o reforço ao cisalhamento com folhas ou laminados de CFRP colados externamente propiciou aumento substancial na resistência última das vigas-parede estudadas, entretanto houve significativa redução da ductilidade. Eles ainda concluíram que o melhor esquema utilizado para reforçar as vigas-parede de concreto leve foi com folhas ou laminados de FRP a $45^{\circ}$.

Tabela 11: Vigas-parede estudadas por Asghari et al. (2014).

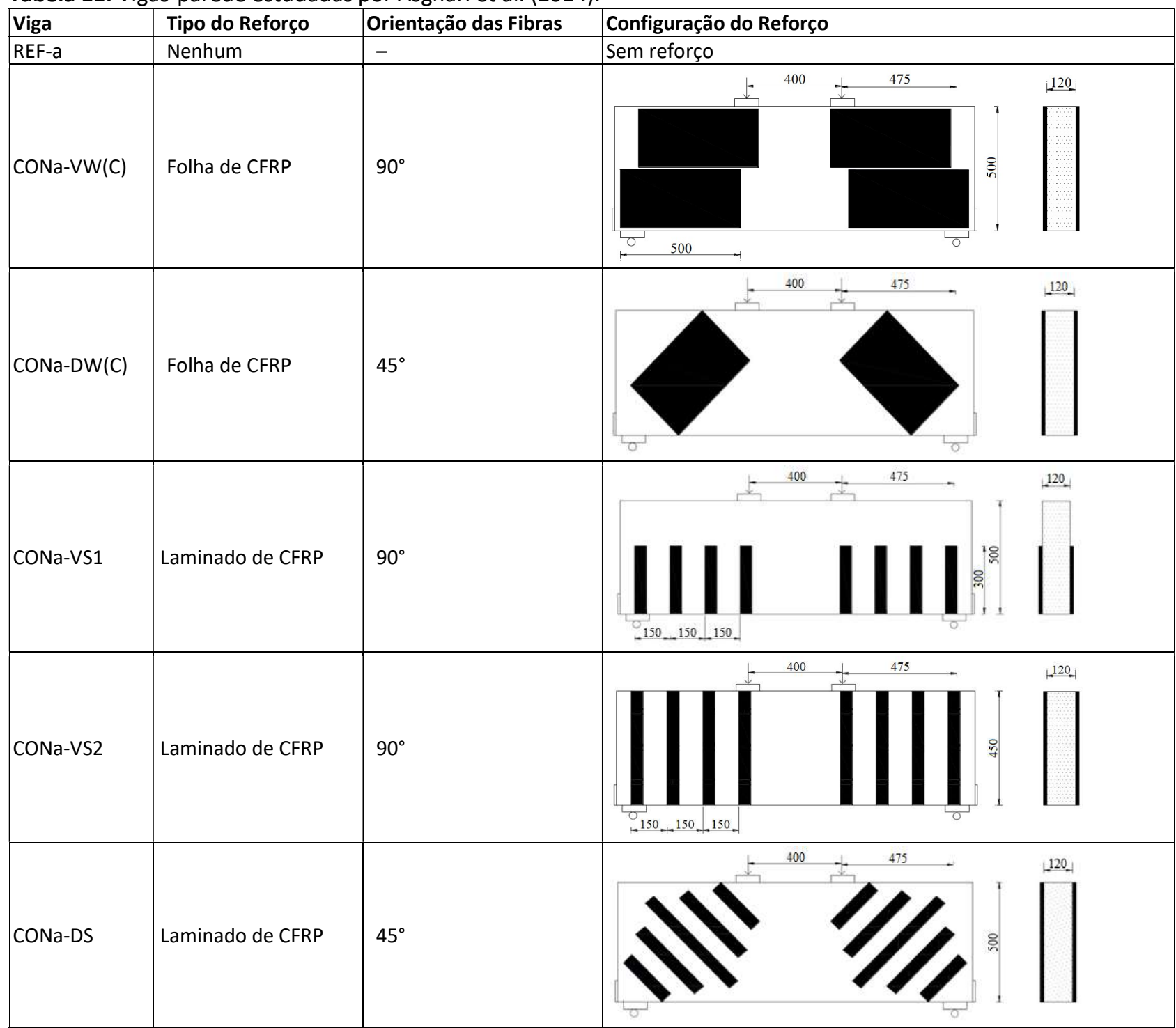

Tabela 12: Propriedades dos reforços utilizados por Asghari et al. (2014).

\begin{tabular}{|l|l|l|l|l|l|}
\hline Tipo de CFRP & Espessura (mm) & Largura (mm) & Resistência à Tração (MPa) & Módulo de Elasticidade (GPa) & Deformação Última (\%) \\
\hline
\end{tabular}

\begin{tabular}{|l|l|l|l|l|l|}
\hline Laminado & 1,200 & 50 & 3.000 & 165 & 1,8 \\
\hline Folha & 0,176 & - & 4.000 & 240 & 1,6 \\
\hline
\end{tabular}



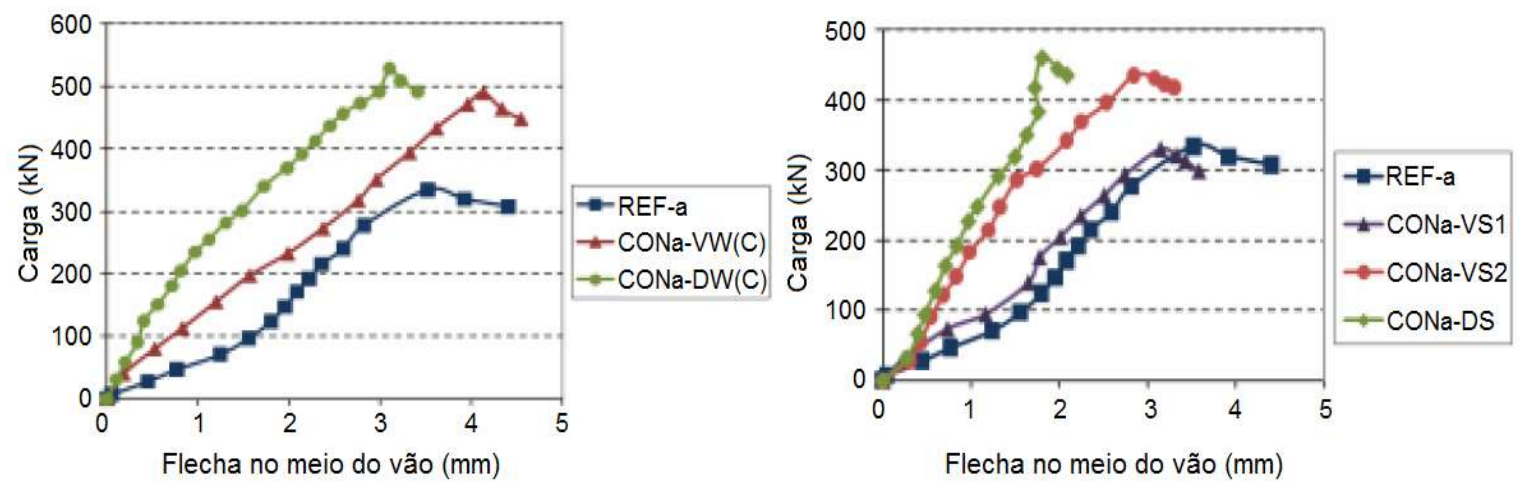

Figura 14: Resultados obtidos por Asghari et al. (2014).

Tabela 13: Resultados encontrados por Asghari et al. (2014).

\begin{tabular}{|l|l|l|l|}
\hline Viga & $\begin{array}{l}\text { Carga de primeira fissura } \\
(\mathbf{k N})\end{array}$ & $\begin{array}{l}\text { Carga última } \\
\mathbf{( k N )}\end{array}$ & Modo de ruptura \\
\hline REF-a & 81 & 334 & Cisalhamento \\
\hline $\begin{array}{l}\text { CONa- } \\
\text { VW(C) }\end{array}$ & 111 & 489 & Esmagamento do concreto sob as folhas de CFRP \\
\hline $\begin{array}{l}\text { CONa- } \\
\text { DW(C) }\end{array}$ & 123 & 528 & $\begin{array}{l}\text { Cisalhamento e esmagamento do concreto sob as folhas de } \\
\text { CFRP }\end{array}$ \\
\hline CONa-VS1 & 90 & 330 & Cisalhamento e delaminação dos laminados de CFRP \\
\hline CONa-VS2 & 98 & 434 & Cisalhamento e delaminação dos laminados de CFRP \\
\hline CONa-DS & 104 & 460 & Cisalhamento e delaminação dos laminados de CFRP \\
\hline
\end{tabular}

\section{Panjehpour et al. (2014)}

Panjehpour et al. (2014) estudaram o comportamento de 12 vigas-parede de mesmas características submetidas a duas cargas simétricas em seis diferentes posições. Os ensaios foram executados em dois grupos de seis vigas-parede, com e sem reforço com folhas de CFRP coladas. A razão a/d de cada grupo era de 0,$75 ; 1,00 ; 1,25 ; 1,50 ; 1,75$ e 2,00 . Ambos os grupos de vigas eram idênticos em todos os aspectos, excetuando-se o reforço com folhas de CFRP.

Todas as vigas tinham $1840 \mathrm{~mm} \times 140 \mathrm{~mm} \times 350 \mathrm{~mm}$ de dimensões. A armadura principal tinha nove barras de aço de $16 \mathrm{~mm}$ de diâmetro e a armadura de cisalhamento era composta de uma malha ortogonal de barras de aço de $6 \mathrm{~mm}$ de diâmetro, espaçadas a cada $100 \mathrm{~mm}$ em cada lado da viga. Armadura adicional (armadura de fretagem) com barras de aço de $6 \mathrm{~mm}$ foi colocada abaixo do carregamento e acima dos apoios para prevenir concentração de tensões. A Figura 15 mostra a representação esquemática da armadura das vigas-parede estudadas por Panjehpour et al. (2014).
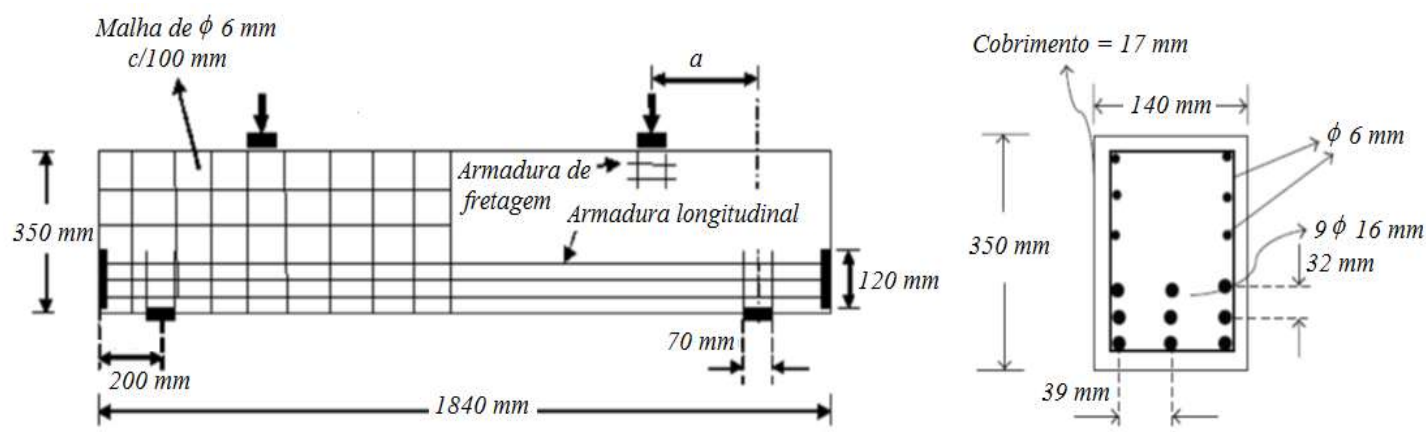

Figura 16: Armadura das vigas estudadas por Panjehpour et al. (2014). 
O concreto das vigas estudadas tinha resistência à compressão de 37,0 MPa e resistência à tração por compressão diametral de 3,3 MPa. Uma camada de folha unidirecional de CFRP com espessura de 0,111 $\mathrm{mm}$ e resina de impregnação epóxi bi-componente foram utilizadas no reforço. As áreas retangulares entre a carga e o apoio (região D) foram completamente cobertas por folhas de CFRP nos dois lados das vigas. A Tabela 14 descreve as propriedades da folha de CFRP e da resina epóxi utilizadas (Sikawrap-230C e Sikadur330, respectivamente). Os resultados obtidos neste estudo são apresentados na Figura 16 ena Tabela 15.

Tabela 14: Propriedades do reforço utilizado por Panjehpou et al. (2014).

\begin{tabular}{|l|l|l|l|l|l|}
\hline Materiais & $\begin{array}{l}\text { Resistência à Tração } \\
\text { (MPa) }\end{array}$ & $\begin{array}{l}\text { Módulo de Elasticidade } \\
\text { (GPa) }\end{array}$ & $\begin{array}{l}\text { Deformação } \\
\text { Última }\end{array}$ & $\begin{array}{l}\text { Resistência de Ligação } \\
\text { (MPa) }\end{array}$ & $\begin{array}{l}\text { Espessura } \\
\text { (mm/camada) }\end{array}$ \\
\hline $\begin{array}{l}\text { Folha de } \\
\text { CFRP }\end{array}$ & 3.900 & 230 & $1,5 \%$ & - & 0,111 \\
\hline $\begin{array}{l}\text { Resina } \\
\text { Epóxi }\end{array}$ & 30 & 4,5 & $0,9 \%$ & $>4$ & - \\
\hline
\end{tabular}
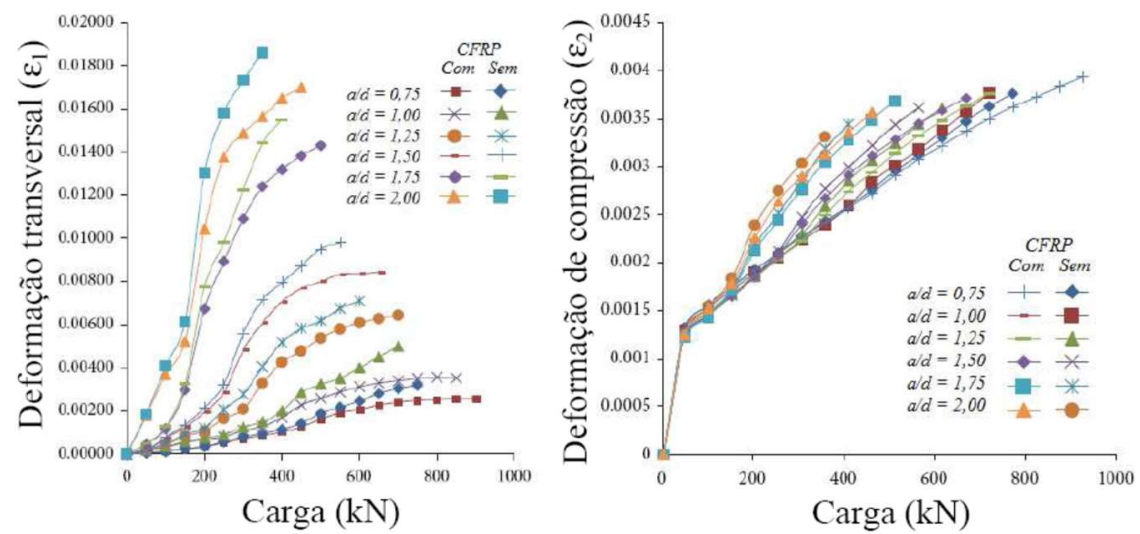

Figura 16: Resultados obtidos por Panjehpour et al. (2014).

Tabela 15: Resultados encontrados por Panjehpour et al. (2014).

\begin{tabular}{|l|l|l|}
\hline Razão a/d & $\begin{array}{l}\text { Carga última } \\
\text { sem reforço (kN) }\end{array}$ & $\begin{array}{l}\text { Carga última } \\
\text { com reforço (kN) }\end{array}$ \\
\hline 0,75 & 757,95 & 905,31 \\
\hline 1,00 & 709,01 & 857,89 \\
\hline 1,25 & 604,08 & 740,02 \\
\hline 1,50 & 555,91 & 691,04 \\
\hline 1,75 & 403,02 & 510,01 \\
\hline 2,00 & 360,02 & 468,05 \\
\hline
\end{tabular}

Os autores concluíram que, para a mesma configuração de carregamento, o reforço conduziu à diminuição da deformação transversal da viga-parede e ao aumento da sua capacidade resistente. Também constataram que, quanto maior a relação entre o vão de cisalhamento e a altura útil da viga (a/d), maior sua deformação transversal e menor sua carga de ruptura.

Ali et al. (2015)

Ali et al. (2015) estudaram o reforço ao cisalhamento de vigas-parede sem estribos com barras de CFRP embutidas no cobrimento do concreto. Para isso, foram ensaiadas cinco vigas-parede sem armadura de cisalhamento de mesmas características, sendo quatro delas reforçadas ao cisalhamento com barras de CFRP em diferentes configurações. Todas as vigas estudadas possuíam $1300 \mathrm{~mm}$ x $400 \mathrm{~mm}$ x $150 \mathrm{~mm}$ de 
dimensões, três barras de aço de 16 mm de diâmetro, como armadura longitudinal (v. Figura 17), e o concreto com resistência média à compressão de 30,5 MPa.

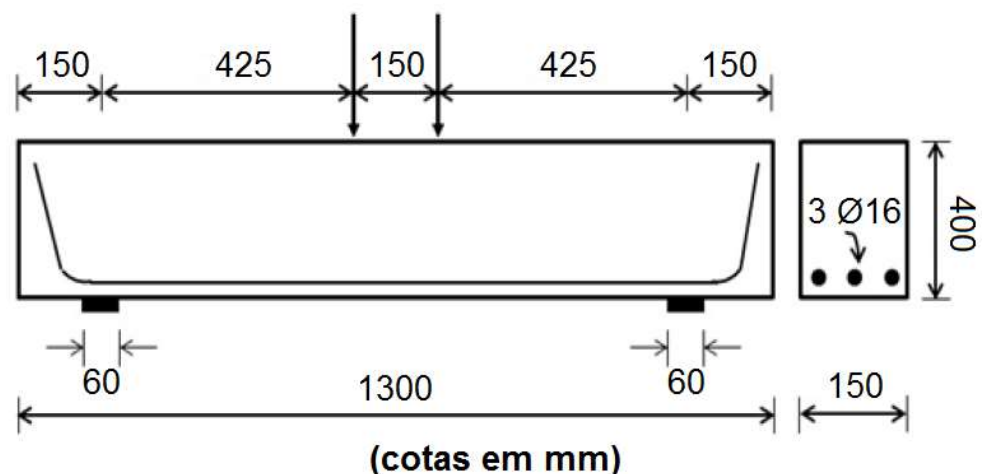

Figura 17: Armadura das vigas estudadas por Ali et al. (2015).

O reforço utilizado era composto de barras de CFRP de 6,3 mm de diâmetro embutidas no cobrimento do concreto nas duas laterais das vigas, variando-se o ângulo de instalação $\left(90^{\circ}\right.$ ou $\left.45^{\circ}\right)$ e o espaçamento horizontal entre as barras (100 mm ou $150 \mathrm{~mm}$ ), conforme apresentado na Tabela 16. Os autores concluíram que o uso de barras de FRP embutidas no cobrimento do concreto foi uma técnica eficaz para aumentar a resistência ao cisalhamento de vigas de concreto armado, que a redução da distância entre as barras de reforço aumentou a resistência ao cisalhamento das vigas estudadas e que o reforço a $45^{\circ}$ foi o mais eficiente, conforme mostrado na Figura 18.

Tabela 16: Reforço das vigas-parede estudadas por Ali et al. (2015).

\begin{tabular}{|c|c|c|}
\hline \multirow{2}{*}{ Código da Viga } & Barras de CFRP & Ângulo \\
\cline { 2 - 3 } & - & - \\
\hline C & $2 \varnothing 6,3 \mathrm{~mm}^{2}$ c $150 \mathrm{~mm}$ & $90^{\circ}$ \\
\hline N90-15 & $2 \varnothing 6,3 \mathrm{~mm}^{2}$ c $100 \mathrm{~mm}$ & $90^{\circ}$ \\
\hline N90-10 & $2 \varnothing 6,3 \mathrm{~mm}^{2}$ c $150 \mathrm{~mm}$ & $45^{\circ}$ \\
\hline N45-15 & $2 \varnothing 6,3 \mathrm{~mm}^{2}$ c $100 \mathrm{~mm}$ & $45^{\circ}$ \\
\hline
\end{tabular}

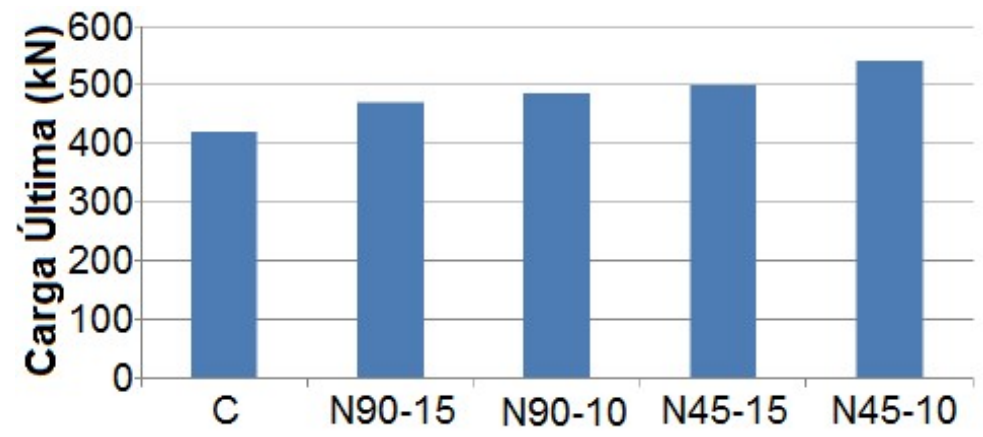

Figura 18: Resultados obtidos por Ali et al. (2015).

\section{Khudair et al. (2015)}

Khudair et al. (2015) estudaram o comportamento de vigas-parede de concreto auto-adensável reforçadas ao cisalhamento com folhas de CFRP. Para isso, foram feitas 11 vigas-parede com concreto autoadensável, projetadas para romper ao cisalhamento, das quais 10 foram reforçadas com folhas de CFRP coladas em diferentes configurações. Todas as vigas estudadas tinham 1.600 mm x 300 mm x 175 mm de 
dimensões, foram confeccionadas com concreto auto-adensável com resistência à compressão de 45,9 MPa e a armadura utilizada foi a esquematizada na Figura 19.

Folhas de CFRP foram utilizadas como reforço nas vigas-parede sob a forma de tiras coladas nas faces de cisalhamento com $300 \mathrm{~mm}$ de altura espaçadas de $20 \mathrm{~mm}$ ou $50 \mathrm{~mm}$, tiras na forma de ' $\mathrm{U}$ ' com $300 \mathrm{~mm}$ de altura espaçadas de $20 \mathrm{~mm}$ ou $50 \mathrm{~mm}$, e tiras envelopando totalmente a viga espaçadas de $20 \mathrm{~mm}$ ou 50 $\mathrm{mm}$. Após a ruptura das vigas estudadas (v. Figura 20), os autores encontraram os resultados apresentados na Tabela 17. E concluíram que, em todas as vigas-parede reforçadas, o reforço com o uso de CFRP levou ao aumento, em média, de 33\% em relação à carga máxima da viga sem reforço e à redução da flecha da viga para o mesmo nível de carga. O uso de folhas de CFRP inclinadas de $45^{\circ}$ em relação ao eixo longitudinal da viga propiciou um maior acréscimo na carga última e um maior decréscimo na flecha e na abertura das fissuras em relação ao uso de folhas verticais $\left(90^{\circ}\right)$.

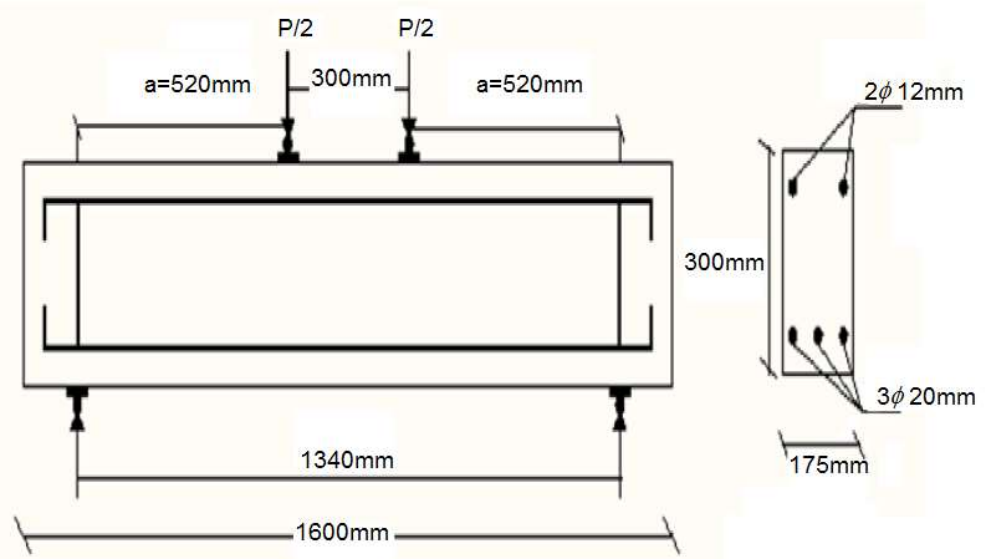

Figura 19: Armadura das vigas estudadas por Khudair et al. (2015).

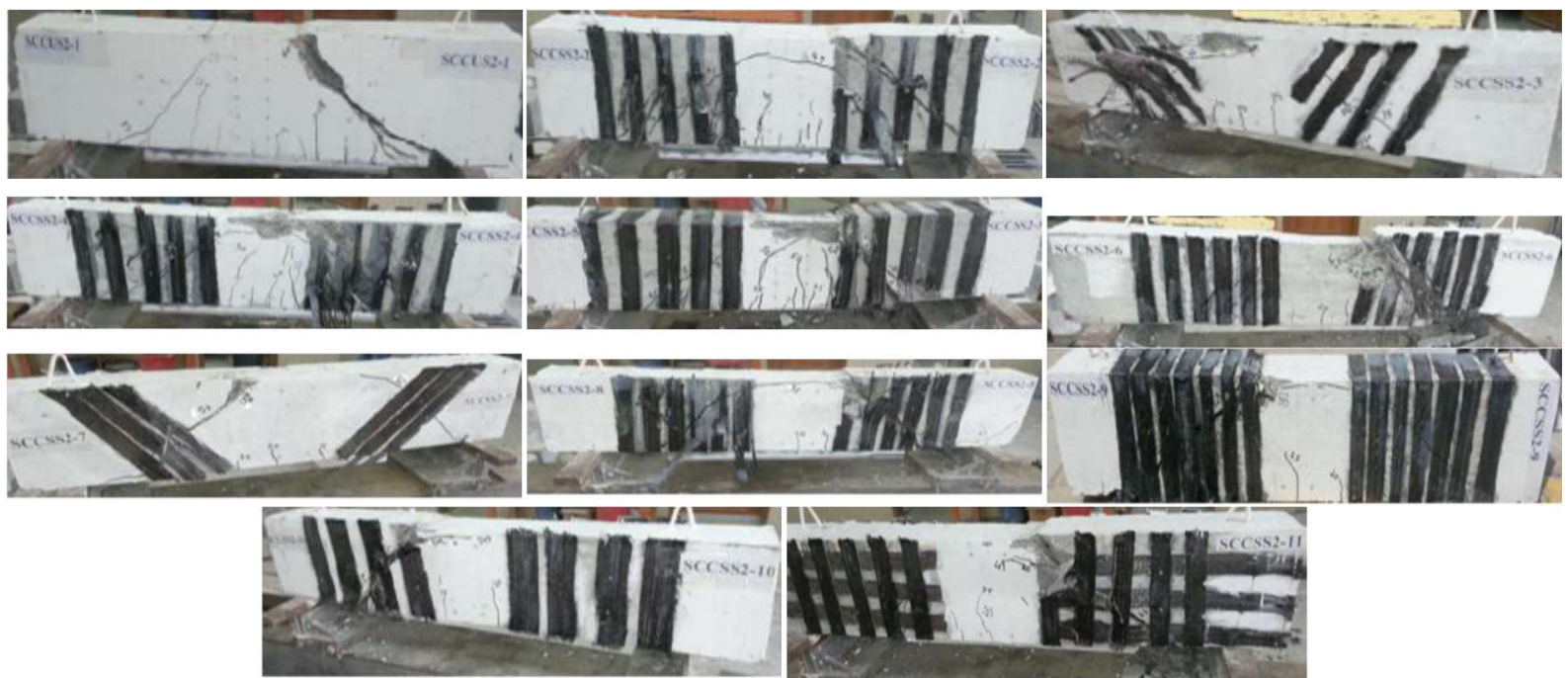

Figura 20: Ruptura das vigas estudadas por Khudair et al. (2015).

Tabela 17: Resultados encontrados por Khudair et al. (2015).

\begin{tabular}{|l|l|l|l|}
\hline Viga & Tipo de reforço & $\begin{array}{l}\text { Carga de Fissuração } \\
\text { (kN) }\end{array}$ & $\begin{array}{l}\text { Carga } \\
\text { (kN) }\end{array}$ \\
\hline SCCUS2-1 & Sem reforço (viga de referência) & 175 & 400 \\
\hline SCCUS2-2 & Folhas a $90^{\circ}$ em 2 lados, com altura de $300 \mathrm{~mm}$, espaçadas a $50 \mathrm{~mm}$ & 190 & 490 \\
\hline SCCUS2-3 & Folhas a $45^{\circ}$ em 2 lados, com altura de $300 \mathrm{~mm}$, espaçadas a $50 \mathrm{~mm}$ & 211 & 496 \\
\hline SCCUS2-4 & Folhas em forma de 'U', com altura de $300 \mathrm{~mm}$, espaçadas a $50 \mathrm{~mm}$ & 215 & 500 \\
\hline SCCUS2-5 & Envolvimento total com folhas espaçadas a $50 \mathrm{~mm}$ & 225 & 520 \\
\hline
\end{tabular}




\begin{tabular}{|l|l|l|l|}
\hline SCCUS2-6 & Folhas a $90^{\circ}$ em 2 lados, com altura de $300 \mathrm{~mm}$, espaçadas a $20 \mathrm{~mm}$ & 200 & 504 \\
\hline SCCUS2-7 & Folhas a $45^{\circ}$ em 2 lados, com altura de $300 \mathrm{~mm}$, espaçadas a $20 \mathrm{~mm}$ & 217 & 507 \\
\hline SCCUS2-8 & Folhas em forma de 'U', com altura de $300 \mathrm{~mm}$, espaçadas a $20 \mathrm{~mm}$ & 227 & 241 \\
\hline SCCUS2-9 & Envolvimento total com folhas espaçadas a $20 \mathrm{~mm}$ & 532 \\
\hline $\begin{array}{l}\text { SCCUS2- } \\
10\end{array}$ & $\begin{array}{l}\text { Folhas a } 90^{\circ} \mathrm{em} 2 \text { lados, com largura de } 80 \mathrm{~mm} \text { e altura de } 300 \mathrm{~mm}, \\
\text { espaçadas a } 50 \mathrm{~mm}\end{array}$ & 221 \\
\hline $\begin{array}{l}\text { SCCUS2- } \\
11\end{array}$ & $\begin{array}{l}\text { Folhas verticais e horizontais em } 2 \text { lados, com altura de } 300 \mathrm{~mm} \text {, espaçadas } \\
\text { a } 50 \mathrm{~mm}\end{array}$ & 200 & 509 \\
\hline
\end{tabular}

\section{Rasheed (2016)}

Rasheed (2016) estudou o comportamento e a eficiência da reparação de vigas-parede de concreto armado com folhas de CFRP. Para isto, realizou um programa experimental para recuperar nove vigas-parede rompidas ao cisalhamento com folhas de CFRP coladas externamente. Os principais parâmetros foram a armadura de cisalhamento horizontal e vertical e a razão a/d.

Todas as vigas-parede estudadas possuíam mesma armadura principal, com tensão de escoamento de $500 \mathrm{MPa}$, concreto com resistência média à compressão de $34 \mathrm{MPa}$, comprimento de $1.200 \mathrm{~mm}$, largura de $115 \mathrm{~mm}$ e altura de $333 \mathrm{~mm}, 400 \mathrm{~mm}$ ou $500 \mathrm{~mm}$. A armadura de cisalhamento utilizada para cada viga era composta de barras de aço com tensão de escoamento de $400 \mathrm{MPa}$, nas quantidades indicadas na Tabela 18. A Figura 21 ilustra a armadura utilizada para a viga DB1.

Tabela 18: Detalhamento das vigas estudadas por Rasheed (2016).

\begin{tabular}{|l|l|l|l|}
\hline \multirow{2}{*}{ Viga } & \multirow{2}{*}{ Altura efetiva $(\mathbf{m m})$} & Armadura de cisalhamento & Horizontal \\
\cline { 3 - 4 } & & Vertical & - \\
\hline DB1 & 365 & - & $\varnothing 4 c 85 \mathrm{~mm}$ \\
\hline DB2 & 365 & $\varnothing 4 c 200 \mathrm{~mm}$ & $\varnothing 6 c 110 \mathrm{~mm}$ \\
\hline DB3 & 365 & $\varnothing 6 c 160 \mathrm{~mm}$ & - \\
\hline DB4 & 365 & $\varnothing 4 c 60 \mathrm{~mm}$ & - \\
\hline DB5 & 365 & $\varnothing 6 c 80 \mathrm{~mm}$ & $\varnothing 4 c 45 \mathrm{~mm}$ \\
\hline DB6 & 365 & - & $\varnothing 6 c 65 \mathrm{~mm}$ \\
\hline DB7 & 365 & - & $\varnothing 4 c 110 \mathrm{~mm}$ \\
\hline DB8 & 465 & $\varnothing 4 c 130 \mathrm{~mm}$ & $\varnothing 4 c 65 \mathrm{~mm}$ \\
\hline DB9 & 298 & $\varnothing 4 c 265 \mathrm{~mm}$ & \\
\hline
\end{tabular}
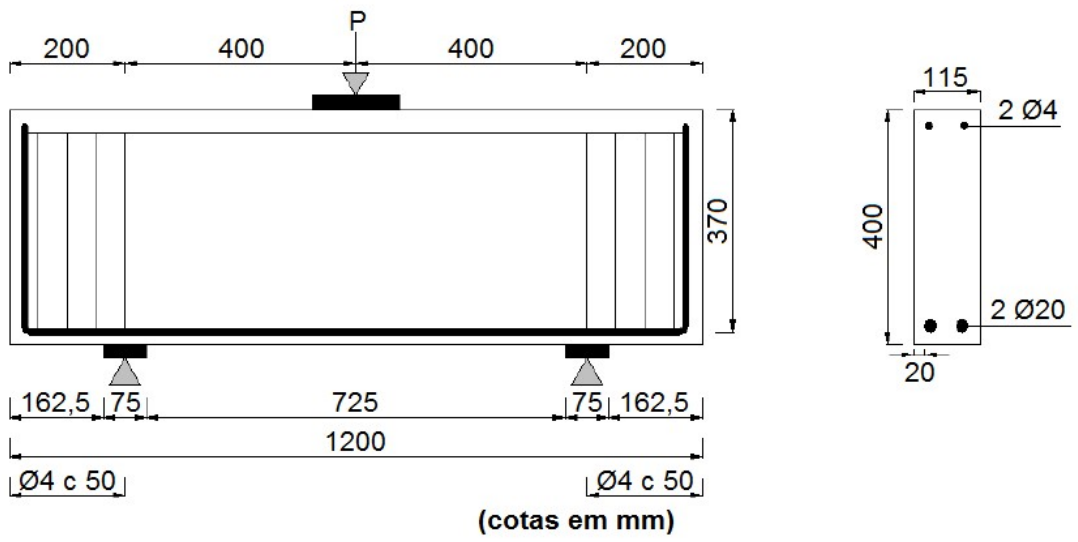

Figura 21: Armadura da viga DB1. Fonte: Rasheed (2016).

Primeiramente, todas as vigas foram submetidas a uma carga central até a ruptura. Em seguida, realizou-se a recuperação destas vigas, conforme esquematizado na Figura 22, com folhas de CFRP com espessura de 0,13 mm, módulo de elasticidade de $230 \mathrm{GPa}$, resistência à tração de $3.500 \mathrm{MPa}$ e deformação 
última de 1,5\%. E, finalmente, as vigas recuperadas foram submetidas à mesma configuração de carregamento até sua nova ruptura.

O autor concluiu que todas as vigas-parede reparadas apresentaram aumento na resistência última em relação às vigas de referência, conforme apresentado na Tabela 19, que o aumento da armadura de cisalhamento horizontal propiciou um menor aumento na resistência das vigas reparadas, enquanto que o aumento da armadura de cisalhamento vertical conduziu a um maior aumento na resistência das vigas reparadas, e que, para a mesma taxa de armadura, o aumento da razão a/d proporcionou um melhor aumento na resistência das vigas reparadas.

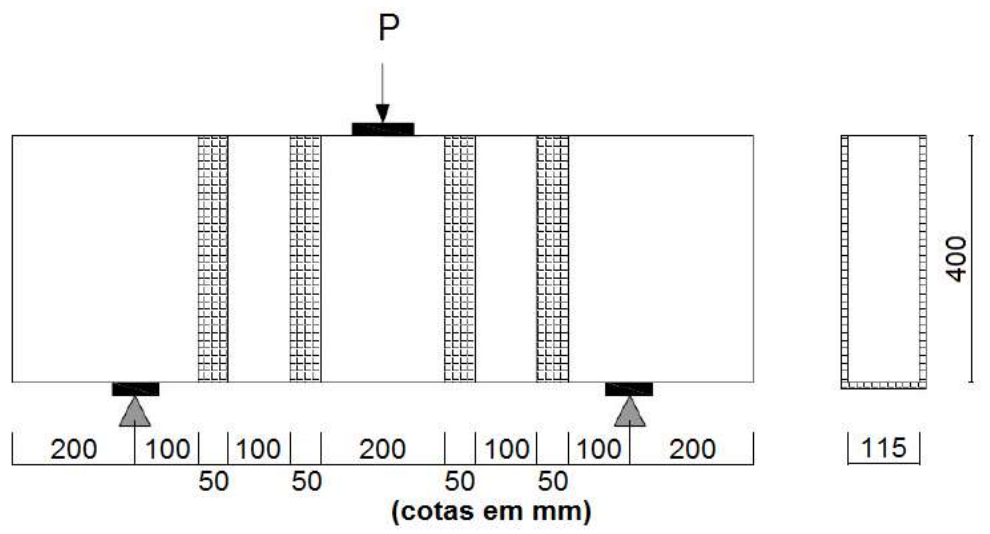

Figura 22: Configuração do reforço das vigas estudadas por Rasheed (2016).

Tabela 19: Resultados encontrados por Rasheed (2016).

\begin{tabular}{|l|l|l|l|l|l|l|}
\hline \multirow{2}{*}{ Viga } & \multicolumn{4}{|l|}{ Vigas de Referência } & \multicolumn{4}{l|}{ Vigas Reparadas } \\
\cline { 2 - 7 } & $\begin{array}{l}\text { Carga Última } \\
\text { (kN) }\end{array}$ & Modo de Ruptura & $\begin{array}{l}\text { Carga Última } \\
(\mathrm{kN})\end{array}$ & Modo de Ruptura & $\begin{array}{l}\text { Aumento } \\
\text { Última }\end{array}$ \\
\hline DB1 & 189 & $\begin{array}{l}\text { Compressão } \\
\text { cisalhamento }\end{array}$ & 418 & Descolamento do reforço & 1,21 \\
\hline DB2 & 398 & $\begin{array}{l}\text { Compressão } \\
\text { cisalhamento }\end{array}$ & 535 & Descolamento do reforço & 0,34 \\
\hline DB3 & 435 & Esmagamento da biela & 469 & Descolamento do reforço & 0,08 \\
\hline DB4 & 415 & Fendilhamento diagonal & 555 & $\begin{array}{l}\text { Esmagamento do } \\
\text { concreto }\end{array}$ & 0,34 \\
\hline DB5 & 418 & Esmagamento da biela & 604 & $\begin{array}{l}\text { Esmagamento do } \\
\text { concreto }\end{array}$ & 0,45 \\
\hline DB6 & 198 & $\begin{array}{l}\text { Compressão } \\
\text { cisalhamento }\end{array}$ & 518 & Descolamento do reforço & 1,61 \\
\hline DB7 & 269 & $\begin{array}{l}\text { Compressão } \\
\text { cisalhamento }\end{array}$ & 472 & Descolamento do reforço & 0,76 \\
\hline DB8 & 417 & Esmagamento da biela & 534 & Descolamento do reforço & 0,29 \\
\hline DB9 & 357 & Esmagamento da biela & 503 & Descolamento do reforço & 0,41 \\
\hline
\end{tabular}

\section{CONCLUSÕES}

Os estudos sobre vigas-parede reforçadas com FRP realizados se limitaram em verificar o aumento da resistência ao cisalhamento das mesmas, seja experimentalmente ou por meio de modelagem numérica baseada no método dos elementos finitos. Para vigas-parede sem aberturas, concluiu-se que: o reforço com tiras de CFRP coladas a 45 foi o mais eficaz e o reforço com tiras de CFRP coladas a 0, o menos, sendo inexpressivo para o caso de carga central; o uso de CFRP acarretou aberturas das fissuras diagonais menores e aumentou a capacidade resistente das vigas estudadas; o reforço com a utilização de CFRP reduziu a deformação transversal e aumentou a resistência da viga-parede e, quanto maior a relação a/d, maior a 
deformação transversal e menor a carga de ruptura da viga reforçada; as folhas de CFRP inclinadas propiciaram um maior acréscimo na carga última e um maior decréscimo na flecha e na abertura das fissuras do que as folhas verticais (inclinação de 90).

\section{REFERÊNCIAS}

ALFERJANI, M. B. S.; SAMAD, A. A. A.; ELRAWAFF, B. S., MOHAMAD, N.; HILTON, M.; SAIAH, A. A. S.. Use of carbon fiber reinforced polymer laminate for strengthening reinforced concrete beams in shear: A review. International Refereed Journal of Engineering and Science, v.2, p.45-53, 2013.

ALI, A. A. M.; MEZHER, T. M.. Shear strengthening of RC without stirrups for deep beams with near surface mounted CFRP rods. International Journal of Engineering Research \& Technology, v.4, n.6, p.545-547, 2015.

$\mathrm{ACl}$. American Concrete Institute. ACl 318M: Building code requirements for structural concrete. Farmington Hills, 2011.

ASGHARI, A. A.; TABRIZIAN, Z.; BEYGI, M. H.; AMIRI, G. G.; NAVAYINEYA, B.. An experimental study on shear strengthening of RC lightweight deep beams using CFRP. Journal of Rehabilitation in Civil Engineering, v.2, n.2, p.919, 2014. DOI: http://dx.doi.org/10.22075/jrce.2014.204

ABNT. Associação Brasileira de Normas Ténicas. ABNT NBR 6118: Projeto de estruturas de concreto - Procedimento. Rio de Janeiro, 2014

BOTELHO, L. L. R.; CUNHA, C. C. A.; MACEDO, M.. O método da revisão integrativa nos estudos organizacionais. Gestão e Sociedade, v.5, n.11, p.121-136, 2011. DOI: http://doi.org/10.21171/ges.v5i11.1220

CSA. Canadian Standard Association. CSA-A23.3: Design of concrete structures. Ontario, 2004

CIRIA. Construction Industry Research and Information Association. CIRIA Guide 2: The design of deep beams in reinforced concrete. London, 1984.

EKENEL, M.; STEPHEN, V.; MYERS, J. J.; ZOUGHI, R.. Microwave NDE of RC beams strengthened with CFRP laminates containing surface defects and tested under cyclic loading. Electrical and Computer Engineering, Rolla, p.1-8, 2004.

HEIZA, K. M.; MELEKA, N. N.; ELWKAD, N. Y.. Shear strengthening of self-compacting reinforced concrete deep beams with external bonded layers. Concrete Research Letters, v.3, n.4, p.507-527, 2012

ISLAM, M. R.; MANSUR, M. A. e MAALEJ, M. Shear strengthening of RC deep beams using externally bonded FR systems. Cement \& Concrete Composites, v.27, n.3, p.413420, 2005.

DOI: $\underline{\text { http://doi.org/10.1016/j.cemconcomp.2004.04.002 }}$

KORE, S. D.; PATIL, S. S.. Analysis and design of R. C. deep beams using code provisions of different countries and their comparison. International Journal of Engineering and Advanced Technology, v.2, n.3, p.166-169, 2013.

KHUDAIR, J. A.; ATEA, R. S. Shear behavior of self compacting concrete deep beams strengthened with carbon fiber reinforced polymer sheets. International Journal of Engineering Research \& Technology, v.4, n.2, p.187-191, 2015 .

LEONHARDT, F.; MÖNNIG, E.. Construções de concreto: Casos especiais de dimensionamento de estruturas de concreto armado. 2 ed. Rio de Janeiro: Interciência, 1978.

LEE, H. K.; CHEONG, S. H.; HA, S. K.; LEE, C. G.. Behavior and performance of RC T-section deep beams externally strengthened in shear with CFRP sheets. Composite Structures, v.93, n.2, p.911-922, 2011. DOI: http://doi.org/10.1016/j.compstruct.2010.07.002

MOREN, J. E.. Shear behavior of reinforced concrete deep beams strengthened with CFRP laminates. Dissertação (Mestrado em Engenharia Civil) - New Jersey Institute of Technology, New Jersey, 2002

PANJEHPOUR, M.; CHAI, H. K.; VOO, Y. L.. Strut deformation in CFRP-strengthened reinforced concrete deep beams. The Scientific World Journal, v.2014, p.1-9, 2014. DOI: http://dx.doi.org/10.1155/2014/265879

PATEL, M. R.; GAJJAR, R. K.. Shear strengthening of different beams using FRP. International Journal of Advanced Engineering Research and Studies, v.1, n.2, p.290-294, 2012.

PATEL, M. R.; TANK, T.. Finite element modeling of RC deep beams strengthened in shear with CFRP strips. The Indian Concrete Journal, v.88, n.3, p.69-76, 2014.

RASHEED, M. M.. Retrofit of reinforced concrete deep beams with different shear reinforcement by using CFRP. Civil and Environmental Research, v.8, n.5, p.6-14, 2016.

ZHANG, Z.. Shear strengthening of RC beams using carbon fiber reinforced polymer laminates. Tese (Doutorado em Engenharia Civil) - New Jersey Institute of Technology, New Jersey, 2003.

A CBPC - Companhia Brasileira de Produção Científica (CNPJ: 11.221.422/0001-03) detém os direitos materiais desta publicação. Os direitos referem-se à publicação do trabalho em qualquer parte do mundo, incluindo os direitos às renovações, expansões e disseminações da contribuição, bem como outros direitos subsidiários. Todos os trabalhos publicados eletronicamente poderão posteriormente ser publicados em coletâneas impressas sob coordenação da Sustenere Publishing, da Companhia Brasileira de Produção Científica e seus parceiros autorizados. Os (as) autores (as) preservam os direitos autorais, mas não têm permissão para a publicação da contribuição em outro meio, impresso ou digital, em português ou em tradução. 